\title{
Periodontal lesions associated with deep bite: Report of three cases
}

\author{
Anika Daing, ${ }^{1 *}$, Zeba Jafri², Ashu Bhardwaj ${ }^{3}$, Madhuri A. Sawai ${ }^{4}$, Nishat Sultan ${ }^{5}$ \\ 1,2,5 Assistant Professor, ${ }^{3}$ Professor ${ }^{4}$ Associate Professor, Dept. of Periodontology, Faculty of Dentistry, Jamia Millia Islamia, New \\ Delhi, India
}

*Corresponding Author:

Email: anika_doc@yahoo.com

\begin{abstract}
Introduction: Deep bite malocclusionis one of the most damaging malocclusion. A traumatic bite can aggravate and perpetuate periodontal disease in patients with poor oral hygiene.

Aim: To report three cases with different periodontal lesions in patients with deep bite.

Case Description: This paper illustrates three cases of Ackerlys class III traumatic bite patients presenting with range of periodontal lesions like localized gingival enlargement, localized periodontitis, tooth mobility and tooth exfoliation in maxillary and mandibular anterior region.

Conclusion: Excessive functional stress may accentuate inflammatory changes in the periodontium and thus enhance the destructive bacterial processes.

Clinical Significance: Traumatic deep overbite complicated with periodontal problems is a challenge for a clinical practitioner. A meticulous and comprehensive approach to periodontal and occlusal examination, etiological factors, diagnosis and treatment planning is essential for better treatment results.
\end{abstract}

Keywords: Malocclusion, Deep bite, Periodontal disease, Gum enlargement.

\section{Introduction}

Normal occlusion and regularity of the teeth in their respective arches are important prerequisite for the development and maintenance of healthy dentition. Deep bite malocclusion is said to be one of the most perpetuating and damaging malocclusions. It can be diagnosed when the lower incisors are overlapped by the upper incisors by more than $2 / 3^{\text {rd }}$ of the clinical crown height. The forces associated with the traumatic overbite can accelerate the progress of periodontal disease in patients who often have poor oral health. An increased overbite may cause food impaction on labial surface of the mandibular incisors and palatal surface of maxillary incisors.

Ackerly gave a classification of traumatic overlap as mentioned in Table $1 .{ }^{1}$ The effect of traumatic deep bite on periodontal trauma has been scarcely mentioned in the literature. This paper presents three cases of Ackerlys class III traumatic bite patients presenting with range of periodontal lesions like localized gingival enlargement, localized periodontitis, tooth mobility and tooth exfoliation in maxillary and mandibular anterior region.

Table 1:

\begin{tabular}{|c|l|l|}
\hline $\begin{array}{c}\text { Ackerly } \\
\text { Classification }\end{array}$ & \multicolumn{1}{|c|}{ Incisor Relationship } & \multicolumn{1}{c|}{ Signs of trauma } \\
\hline I & Lower incisor impinge palatal mucosa & $\begin{array}{l}\text { Inflammation of palatal } \\
\text { mucosa with the imprint of } \\
\text { lower incisal edges }\end{array}$ \\
\hline II & $\begin{array}{l}\text { Lower incisors incisal edge } \\
\text { occludes into palatal gingival } \\
\text { crevices of maxillary teeth }\end{array}$ & $\begin{array}{l}\text { Labial splaying of maxillary pocket } \\
\text { Palatal mucosa }\end{array}$ \\
\hline III & Class II div 2 type incisal relationship & $\begin{array}{l}\text { Stripping of gingival in } \\
\text { Relation to palatal surface } \\
\text { of upper anterior teeth and } \\
\text { labial surface of lower anterior teeth }\end{array}$ \\
\hline IV & $\begin{array}{l}\text { Lower incisors causing progressive } \\
\text { abrasion Of palatal surfaces } \\
\text { of maxillary teeth }\end{array}$ & $\begin{array}{l}\text { Abrasion of palatal surfaces of upper } \\
\text { anterior teeth } \\
\text {-Dentin hypersentivity }\end{array}$ \\
\hline
\end{tabular}

\section{Case Description}

Case 1

18 year old girl reported with a chief complaint of swelling and bleeding in the gums of lower front teeth which started 3 months back which gradually increased to its present size. Patient was unable to brush in lower jaw owing to pain and bleeding. Intraoral examination revealed there was an excessive overlap of mandibular 
incisors by maxillary incisors presenting a deep bite malocclusion of Ackerlys Class III traumatic overlap [Fig. 1]. Large amount of plaque and calculus deposits were present in mandibular anteriors as compared to other teeth [Fig. 2]. Localized gingival enlargement was seen extending from distal surface of right mandibular lateral incisor to distal surface of left mandibular lateral incisor. Gingival enlargement was red in color, soft, edematous, with smooth and shiny surface texture covering $2 / 3^{\text {rd }}$ of crown of mandibular incisors. A probing depth of $4-5 \mathrm{~mm}$ was recorded in mandibular incisors with no clinical attachment loss. Intra oral periapical (IOPA) radiograph showed no bone loss in relation to lower anteriors; suggesting a diagnosis of generalized chronic gingivitis with localized inflammatory gingival enlargement in relation to mandibular incisors.

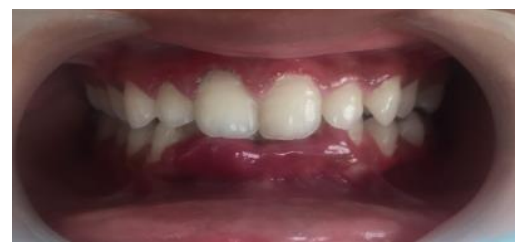

Fig. 1: Deep bite with localized gingival enlargement in relation to mandibular incisors

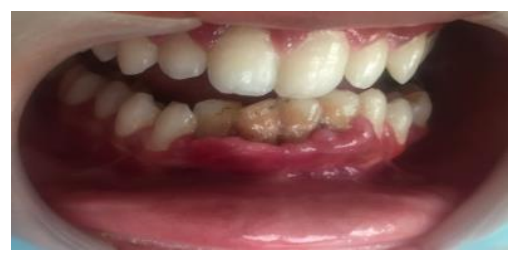

Fig. 2: Large amount of plaque and calculus with pseudopockets in mandibular anteriors

\section{Case 2}

45 year old male patient came with a chief complaint of loosening of his right lower front tooth since 6 months. Patient also complained of gingival swelling and intermittent pain in relation to lower front teeth. Intraoral examination revealed there was an excessive overlap of maxillary incisors touching the labial gingiva of mandibular incisor in Ackerlys Class III traumatic overlap [Fig. 3]. There was minimal plaque and calculus. A generalized probing pocket depth of $2-3 \mathrm{~mm}$ was recorded whereas mandibular incisors had a probing pocket depth ranging from $4 \mathrm{~mm}$ $7 \mathrm{~mm}$. Tooth 42 had maximum pocket depth of $7 \mathrm{~mm}$ (buccal and mesial), with clinical attachment loss of $5 \mathrm{~mm}$ and Grade II mobility [Fig. 4]. Teeth 31, 32 and 41 were Grade I mobile. IOPA radiograph showed a generalized horizontal bone loss in relation to all mandibular anteriors with maximum bone loss in relation to 42 [Fig. 5]. Clinical and radiographic findings were suggestive of diagnosis of Generalized chronic gingivitis with Localized Chronic Periodontitis in relation to $31,32,41$ and 42 .

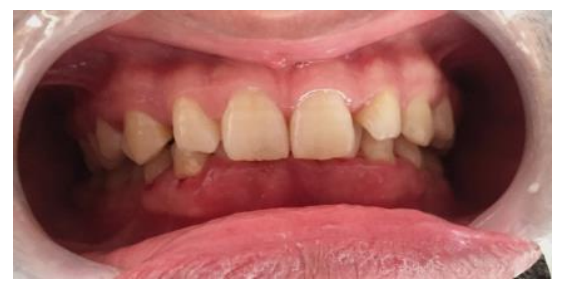

Fig. 3: Deep bite malocclusion with excessive vertical overlap

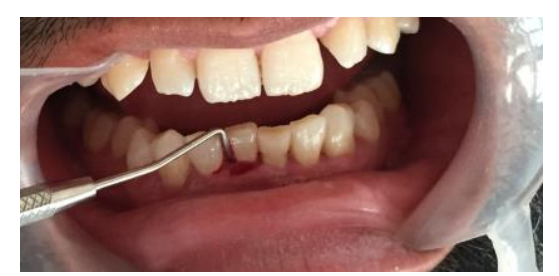

Fig. 4: Localized periodontitis in mandibular incisors

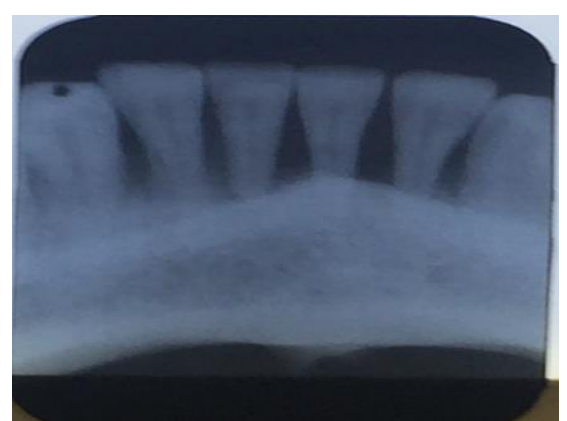

Fig. 5: IOPA showing bone loss associate with mandibular incisors

\section{Case 3}

31 year old male patient with a chief complaint of missing upper front tooth which got exfoliated 2 weeks back due to progressive loosening. 6 months back patient visited a dental clinic where dentist took radiograph for upper teeth and he was told that an attempt can be made to save his mobile tooth by performing a root canal procedure followed by periodontal surgery. However, he was unable to follow the treatment due to personal constraints.

Intraoral examination revealed that tooth 21 was missing and mandibular incisors were striking and traumatizing maxillary palatal mucosa [Fig. 6]. There was an excessive vertical overlap of maxillary incisors over mandibular incisors presenting Ackerlys Class III traumatic overlap. Plaque and calculus deposits were minimal. Patient showed his radiograph which was taken 6 months back before the loss of tooth 21. IOPA displayed an excessive bone loss in relation to tooth 21 with signs of mild root resorption [Fig. 7]. History, clinical and radiographic examination suggested a probable cause for progressive mobility of tooth 21 could be severe bone loss due to localized Chronic 
Periodontitis which got aggravated by traumatic forces of deep bite.

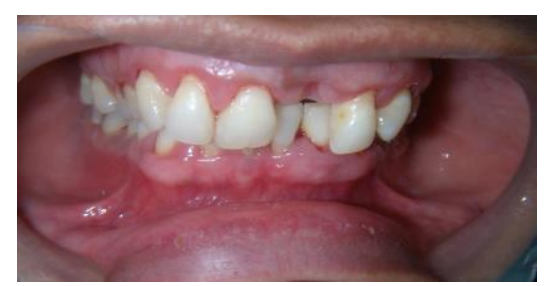

Fig. 6: Missing tooth 21 with mandibular incisors striking palatal mucosa of maxillary incisors

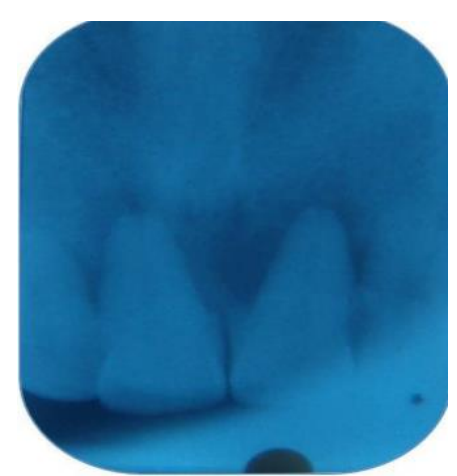

Fig. 7: IOPA showing severe bone loss in relation to tooth 21 and generalized horizontal bone loss in relation to mandibular incisors

\section{Discussion}

Occlusal trauma does not cause periodontal disease per se, however the above cases showed that deep traumatic overbite in certain cases it can lead to localized periodontal breakdown. ${ }^{2,3}$ All the above cases were noted to have a deep bite in class III Ackerly relationship where patients presented with a range of symptoms including gingival pain, bleeding, enlargement, tooth mobility and tooth exfoliation. These were predominant only in maxillary and mandibular anterior teeth and not generalized suggesting a possible role of occlusal trauma in etiopathogenesis of these lesions.

Similar to findings in above mentioned cases few cases have been reported in literature where increased occlusal trauma has contributed to creation of periodontal lesions. In one of our earlier cases increased occlusal forces due to traumatic deep bite had led to a combined periodontal lesion consisting of dehiscence and lateral periradicular defect in relation to right maxillary central incisor in 26 year old male patient. This lesion appeared radiographically as a lateral circumscribed radiolucency, remote from alveolar crest and close to apex. ${ }^{4}$ Ustan et al 2008 reported a case of in a 16 year old male in which both the mucogingival problem and occlusal trauma acted together and caused severe gingival recession in mandibular anteriors. ${ }^{2}$ Nasry et al 2006 reported cases where deep traumatic overbite has led to lateral periodontal bony defects. ${ }^{3}$ These findings can be largely explained due to forces associated with traumatic bite which can wedge plaque and food debris into gingival sulcus and accelerating progress of periodontal treatment.

Treatment of periodontal lesions complicated with deep bite are more challenging as they require a sequential and comprehensive treatment plan involving both periodontal and orthodontic management. ${ }^{3-5}$ Correction of malocclusion is thus important at an early stage to prevent potential damage to the periodontium. The most popular method for correcting a deep overbite is by or anterior bite plane. It can be followed by aa fixed orthodontic treatment for more definitive results. Further T-scan, a computerized occlusal analysis system can be used to assess the occlusal force distribution. It includes a three dimensional sensor color coded tooth contact data where differences in occlusal forces can be distinguished by colors ranging from pink (highest force) to the blue (lowest force). This data can be used for selective occlusal grinding. The initial periodontal treatment will involve patient motivation, scaling root planing, antimicrobial therapy followed by regular maintenance. This may be succeeded by surgical therapy as required.

\section{Conclusion}

Traumatic deep bite can create excessive functional stresses that may accentuate inflammatory changes in the periodontium and thus enhance the destructive bacterial processes leading to periodontal lesions.

\section{References}

1. Gupta ND, Maheshwari S, Prabhat KC, Goya L. "A critical review of the management of deep overbite complicated by periodontal diseases". European Journal of General Dentistry(2012)1,2-5.

2. Ustun K, Sari Z, Orucoglu H, duran I, Hakki S. "Severe gingival recession caused by traumatic occlusion and Mucogingival stress". European Journal of General Dentistry(2008)2, 127-133.

3. NasryHA, Barclay SC. "Periodontal lesions associated with deep traumatic overbite". British Dental Journal. (2006) 200(10),557-61.

4. Daing A, Singh A, Dixit J, Anand V. "Management of periodontal lesion associated with traumatic deep bite: a case report". International Journal of Dental Case Reports (2012)2(3),48-53.

5. Sreedhar Cvvr, Baratam S." Deep overbite-A review". Annals and essence of Dentistry (2009)1(1),8-25. 